\title{
BMJ Open Characterisation of social support following incarceration among black sexual minority men and transgender women in the HPTN 061 cohort study
}

Joy D Scheidell ${ }^{1},{ }^{1}$ Typhanye V Dyer, ${ }^{2}$ Christopher Hucks-Ortiz,
Jasmyn Abrams, ${ }^{1}$ Medha Mazumdar, ${ }^{1}$ Charles Cleland, ${ }^{1}$ Natalia Irvine, ${ }^{1}$
Rodman E Turpin, ${ }^{2}$ MacRegga Severe, ${ }^{1}$ Kenneth Mayer, ${ }^{4,5}$ Maria Khan ${ }^{1}$
To cite: Scheidell JD, Dyer TV, Hucks-Ortiz C, et al. Characterisation of social support following incarceration among black sexual minority men and transgender women in the HPTN 061 cohort study. BMJ Open 2021;11:e053334. doi:10.1136/ bmjopen-2021-053334

- Prepublication history and additional supplemental material for this paper are available online. To view these files, please visit the journal online (http://dx.doi.org/10.1136/ bmjopen-2021-053334).

Received 11 May 2021 Accepted 08 September 2021

Check for updates

(C) Author(s) (or their employer(s)) 2021. Re-use permitted under CC BY-NC. No commercial re-use. See rights and permissions. Published by BMJ.

For numbered affiliations see end of article.

Correspondence to

Dr Joy D Scheidell;

joy.scheidell@nyumc.org

\section{ABSTRACT}

Objective To examine longitudinal associations between recent incarceration and subsequent social support among black sexual minority men and transgender women, and whether associations differed between those who did and did not have support prior to incarceration.

Design A secondary analysis in 2020 of data from the HIV Prevention Trials Network 061, a cohort study of black sexual minority men and transgender women recruited in 2009-2010 and followed for 12 months.

Setting Six US cities (Atlanta, Boston, Los Angeles, New York City, San Francisco and Washington DC).

Participants Individuals $\geq 18$ years of age who identified as black, reported being male or assigned male at birth, reported $\geq 1$ unprotected anal intercourse event with a male partner in the past 6 months, and reported on incarceration at the 6-month follow-up visit.

Exposure Having spent $\geq 1$ night in jail/prison in the past 6 months reported at the 6 -month follow-up visit. Outcome Social support measured using a six-item scale assessing frequency of emotional/informational, affectionate and tangible support (range 6-30); and dichotomous indicators of low support for each item (ie, receiving that form of support none/little of the time).

Results Among participants who returned for the 6-month visit ( $\mathrm{N}=1169), 14 \%$ had experienced incarceration in the past 6 months. Mean support score was 20.9; 18.9 among those with recent incarceration versus 21.2 among those without. Recent incarceration predicted lower support (adjusted $\beta-2.40,95 \% \mathrm{Cl}-3.94$ to -0.85 ). Those recently incarcerated had increased risk of lacking emotional/ informational (eg, no one to talk to adjusted risk ratio (aRR) $1.55,95 \% \mathrm{Cl} 1.13$ to 2.13 ) and affectionate (aRR 1.51, $95 \% \mathrm{Cl} 1.11$ to 2.04 ) but not tangible support. Effects appeared somewhat stronger among those who had support at baseline.

Conclusions Incarceration may reduce support on reentry among black sexual minority men and transgender women, populations unequally targeted for incarceration and at risk for low support.

\section{INTRODUCTION}

Social support is the functional content of one's interpersonal relationships and social
Strengths and limitations of this study

- The longitudinal study of over 1000 black sexual minority men and transgender women in six US cities provides a large sample size for analyses.

- The use of inverse probability of treatment weighting reduces potential bias in the estimates of associations between recent incarceration and subsequent social support.

- The study is limited by a lack of data on the frequency and sources of the support.

- Measures are self-reported and may be subject to recall and social desirability bias.

resources one can call on during stressful events, ${ }^{1}$ and is important for physical, emotional and mental health. ${ }^{2}$ Support can buffer against adverse effects of stress on health by preventing one from appraising a situation as stressful and/or inhibiting maladaptive responses. ${ }^{3}$ Emotional support (eg, listening, understanding), informational support (eg, giving advice), affectionate support (eg, love, empathy) and tangible support (eg, receipt of aid and services) ${ }^{4}$ are linked to reduced morbidity and mortality from health outcomes such as diabetes, cardiovascular disease and depression. ${ }^{5}$ Individuals returning from incarceration may be especially in need of social support during re-entry, and support from a variety of sources such as partners, family, and friends are key for successfully reintegrating in to the community and reducing risk of substance use, poor mental health and sexually transmitted infection (STI) $/ \mathrm{HIV}^{6-9}$

Yet, while social support following incarceration is vital, incarceration itself may disrupt and negatively affect the community and family ties to which an individual returns. ${ }^{8}$ 10-12 Incarceration is associated 
with declines in emotional support, particularly support from non-family members. In studies conducted in predominantly heterosexual samples, incarceration is linked to loss of intimate partnerships and diminished relationship quality, ${ }^{10-13}$ and couples are more likely to report lower levels of happiness and no longer cohabiting after re-entry. ${ }^{13}$ Incarceration-related disruption of social ties may affect other forms of support beyond emotional and affectionate. After returning from incarceration, having social connections is critical for securing employment ${ }^{14}$ and accessing other forms of tangible socioeconomic support. For example, among a sample of Midwestern males being paroled, quality ties to family were associated with employment attainment on re-entry, even after controlling for preincarceration employment. ${ }^{14}$

A group that may be particularly vulnerable to the detrimental impact of incarceration on social support but has not yet been a focus of research in this area are black sexual minority men (BSMM) and transgender women (BTW). Black people, including BSMM and BTW, are disproportionately affected by incarceration in the USA, ${ }^{15}$ primarily due to criminal justice policy and sentencing that exhibit substantial racial biases. ${ }^{16}$ Experiencing incarceration often carries a long-lasting stigma, ${ }^{17}$ and those who have experienced it often perceive high levels of stigma that may be internalised, potentially leading to self-stigmatisation and avoidance of family and friends to protect them from further stigma. ${ }^{18} 19$ In addition to potential incarceration-related marginalisation, BSMM and BTW may experience stigma and isolation due to intersections between their race and sexual identities. This is based on intersectionality theory, ${ }^{20}$ which posits that individuals experience unique stigmas and discrimination based on the combinations of their identities, not simply their individual ones. BSMM and BTW experience both racism, homophobia and a unique intersection of the two that is not experienced by black heterosexual men or sexual/gender minorities of other racial groups. ${ }^{21}$ This stigma may include families of BSMM and BTW having negative attitudes towards same-sex relationships, ${ }^{22}$ and people of colour being excluded from the majority of lesbian, gay, bisexual, transgender, queer/questioning (LGBTQ) communities and social networks, with black LGBTQ people forming their own networks. ${ }^{23}$ Hence, the negative effects of incarceration on social support could be exacerbated among BSMM and BTW who may already be at risk of reduced support.

Our study addresses this gap by examining the relationship between recent (ie, past 6 months) incarceration and postincarceration emotional/informational, affectionate and tangible forms of social support using HIV Prevention Trials Network (HPTN) 061, a study conducted among BSMM and BTW. We tested associations between incarceration and overall support and individual indicators of each form of support, assessing whether associations differed between those who did and did not have support prior to the incarceration.

\section{METHODS}

\section{Patient and public involvement}

This study is a secondary data analysis of HPTN 061 and no participants were directly involved.

\section{Study sample and design}

HPTN 061's procedures have been described in detail elsewhere. ${ }^{24}$ The parent study aimed to assess the feasibility and acceptability of HIV prevention strategies among BSMM/BTW and enrolled 1553 participants from 2009 to 2010 in six US cities: Atlanta, New York City, Washington DC, Los Angeles, San Francisco and Boston. Eligible participants were individuals at least 18 years of age who self-identified as a man or reported being assigned male at birth, self-identified as Black, African American, Caribbean Black, or multiethnic Black, and reported at least one condomless anal intercourse event with a male partner in the past 6 months. ${ }^{24}$ Participants completed a baseline survey using audio computerassisted self-interviewing technology assessing topics including incarceration, sexual behaviours, substance use and social support; surveys were conducted again at 6 and 12 months. At baseline, demographic data were collected.

\section{Measures}

Incarceration. At the 6-month visit, participants reported the number of times that they had spent one or more nights in jail/prison in the past 6 months; those who reported they had spent at least one night incarcerated were defined as having experienced recent incarceration.

Social Support. Social support was measured at baseline and 12 months follow-up visit using items adapted from the RAND Medical Outcomes Study (MOS) ${ }^{25}$ The original MOS social support scale contained 19 support items categorised in subscales of tangible support, affectionate support, emotional/informational support, positive social interactions. The original MOS subscales all had alphas $>0.90$ and could be combined to create an indicator of overall support, which had an alpha of $0.97 .{ }^{26}$ From the original MOS support scale, one item from the tangible support subscale, four items from the emotional/informational support subscale, and one item from the affectionate support subscale were included in the HPTN 061 study; we analysed each of these items individually and did not include subscales in the analysis. While this abbreviated version of the scale has not been validated, it has been used previously in other HPTN 061 studies and is correlated with STI/HIV risk and mental health factors. ${ }^{24} 2728$

For each form of support described below, participants rated on a five-point scale the frequency they had received it in the past 6 months, ranging from none of the time to all of the time, which are the same response options as the original MOS social support scale items.

Emotional and informational support was assessed with four items capturing the frequency someone was available to listen, available to give good advice, be counted on to provide emotional support, and they had contact 
with someone they feel close to in whom they can trust and confide in.

Affectionate support was assessed with one item measuring how often someone was available who shows love and affection.

Tangible support was assessed with one item that captured how often someone was available to help with daily chores.

Overall social support score at the 12-month follow-up was calculated as a continuous score (range 6-30) by summing the five-point response scale for six all social support items (Cronbach's alpha 0.95).

We also created dichotomous indicators of support for each item, in which it was dichotomised to 'having support' if they received that form of support for some, most or all of the time, and 'lacking support' for receiving that form of support none or little of the time.

Covariates. Covariates were assessed at baseline and included in the inverse probability of treatment weights (IPTW) described below. We selected covariates that we hypothesised were associated with both incarceration and social support based on the literature and directed acyclic graphs. Demographic covariates included study site at time of enrolment; age ${ }^{29}$; gender identity defined as cisgender male and transgender female; unstable housing ${ }^{30}$ defined as reporting lacking a stable home; high school education or less ${ }^{31}$; and insufficient income ${ }^{31}$ defined as reporting having insufficient income never or once in a while versus fairly often or very often.

Psychosocial covariates included self-reported hard drug use ${ }^{32}$ (ie, heroin, crack/cocaine, methamphetamine, prescription misuse or other drugs) in the past 6 months; weekly marijuana use; currently has health coverage; lifetime incarceration; Alcohol Use Disorders Identification Test score ${ }^{33} 34$; depressive symptoms based on Centres for Epidemiologic Studies-Depression scale ${ }^{35}$; physical and/or threatened violence due to race and/or sexuality, which is defined as reporting being threatened with and/or experiencing physical violence (ie, punched, kicked, beaten) that the participant attributed was due to their race and their sexuality ${ }^{36}$; perceived racism and homophobia, which was measured using items from the Racism and Life Experience Scales- Daily Life Experiences scale, with 20 items each regarding experiences related to race and sexuality such as being ignored or not given the same service ${ }^{3738}$; and internalised homophobia, which was assessed by summing responses to a 7-item scale regarding how strongly participants agreed with statements such as 'I wish I weren't attracted to men,' and 'As a Black man, I try to act more masculine to hide my sexuality. ${ }^{39} 40$ STI/ HIV risk covariates including reporting sex with female partners in the past 6 months ${ }^{41}$; having received HIV testing $^{32}$; transactional sex in the past 6 months; multiple partnerships defined as higher than the median $(\geq 3)^{42}$; concurrent partnership defined as partners in addition to their primary partner in the past 6 months and currently cohabiting with primary partner.
Biologically ascertained covariates included HIV status at baseline and any STI (ie, syphilis assessed via blood testing, and gonorrhoea and chlamydia assessed via urine/rectal swab testing).

\section{Analyses}

We used R V.3.6.2 for analysis. Our analytical sample included participants who returned for the 6-month follow-up with non-missing data on recent incarceration history $(\mathrm{N}=1169)$. Scales with missing values were replaced with the mean value of the remaining items if fewer than $20 \%$ of items were missing. When $\geq 20 \%$ of scale items were missing, the sum score was coded as missing. Of those in the analytic sample, approximately $34 \%$ were missing data on at least one covariate, and multiple imputation was used by imputing data 40 times using predictive mean matching in the 'mice' package.

The propensity of recent incarceration was calculated using logistic regression with the Ridge penalty conditional on the baseline covariates described above and used to estimate IPTW, which were stabilised using the probability of the recent incarceration measured at the 6-month study visit (see online supplemental table for associations between the covariates and recent incarceration). ${ }^{43}$ This was conducted for each of the 40 imputed datasets. We used IPTW to adjust for potential confounding due to the large number of covariates and desire to account for potential selection into recent incarceration.

In the analyses, we first examined baseline factors associated with lacking all six forms of social support at 12 months (ie, low overall social support) by calculating the frequency and prevalence of each covariate by low overall social support, using modified Poisson regression with robust SEs to address convergence issues. We then estimated associations between recent incarceration reported at the 6-month study visit and continuous social support score measured at 12 months; we also estimated associations with lacking each individual form of social support at 12 months as well as lacking all six forms of social support at 12 months. We used unweighted and weighted modified Poisson regression with robust SEs to estimate risk ratios (RR) in each of the imputed datasets. To do so, parameter estimates and variances were extracted from each model, and pooled following Rubin's rules. ${ }^{44}$ Unweighted and weighted RRs and SEs via the Delta Method for each form of social support were obtained using the 'margins' package.

To assess whether the association between recent incarceration at 6 months and social support reported at 12 months varied by status of baseline social support, we tested the significance of an incarceration by social support interaction term. Specifically, for each form of social support reported at 12 months, we included an interaction term between recent incarceration at 6 months and lacking that form of support at baseline. Because some differences in the relationship between recent incarceration at 6 months and social support at 12 months were observed depending on baseline support, 
Table 1 Characteristics of HPTN 061 sample and associations with low social support at 12 months follow-up (N=1169)

\begin{tabular}{|c|c|c|c|}
\hline Characteristic & Total $(\mathrm{N}=1169)$ & $\begin{array}{l}N(\%)^{*}, \dagger \text { with low social } \\
\text { support }(n=138)\end{array}$ & RR (95\% CI) \\
\hline \multicolumn{4}{|l|}{ Age } \\
\hline Median (min, max) & $39.0(18.0,68.0)$ & $41.0(18.0,58.0)$ & $1.00(0.99$ to 1.01$)$ \\
\hline \multicolumn{4}{|l|}{ Gender } \\
\hline Cisgender male & $1118(95.6)$ & $127(11.4)$ & Referent \\
\hline Transgender female & $49(4.2)$ & $11(22.4)$ & 1.94 (0.99 to 3.42$)$ \\
\hline \multicolumn{4}{|l|}{ Unstable housing } \\
\hline No & $1055(90.2)$ & $118(11.2)$ & Referent \\
\hline Yes & $113(9.7)$ & $20(17.7)$ & $1.63(0.99$ to 2.56$)$ \\
\hline \multicolumn{4}{|l|}{ Less than high school education } \\
\hline No & $568(48.6)$ & $56(9.9)$ & Referent \\
\hline Yes & $601(51.4)$ & $82(13.6)$ & 1.50 (1.07 to 2.12$)$ \\
\hline \multicolumn{4}{|l|}{ Insufficient income } \\
\hline No & $513(43.9)$ & $43(8.4)$ & Referent \\
\hline Yes & $655(56.0)$ & $95(14.5)$ & $1.84(1.29$ to 2.66$)$ \\
\hline \multicolumn{4}{|l|}{ Ever incarcerated } \\
\hline No & $465(39.8)$ & $51(11.0)$ & Referent \\
\hline Yes & $686(58.7)$ & 85 (12.4) & $1.15(0.82$ to 1.64$)$ \\
\hline \multicolumn{4}{|l|}{$\begin{array}{l}\text { Depression scale (Centers for Epidemiologic } \\
\text { Studies - Depression) }\end{array}$} \\
\hline Mean (SD) & $16.4(11.0)$ & $21.2(11.9)$ & $1.03(1.02$ to 1.05$)$ \\
\hline \multicolumn{4}{|l|}{ Depression } \\
\hline Score $<16$ & $624(53.4)$ & $53(8.5)$ & Referent \\
\hline Score $\geq 16$ & $487(41.7)$ & $78(16.0)$ & 1.95 (1.38 to 2.78$)$ \\
\hline \multicolumn{4}{|l|}{ Racism scale } \\
\hline Mean (SD) & $49.5(24.0)$ & $49.3(24.7)$ & $1.00(0.99$ to 1.01$)$ \\
\hline \multicolumn{4}{|l|}{ Racism } \\
\hline Score <median (52) & $584(50.0)$ & $70(12.0)$ & Referent \\
\hline Score $\geq$ median (52) & $566(48.4)$ & $66(11.7)$ & $0.94(0.67$ to 1.31$)$ \\
\hline \multicolumn{4}{|l|}{ Experienced homophobia } \\
\hline Mean (SD) & $53.2(31.5)$ & $54.7(32.8)$ & $1.00(1.00$ to 1.01$)$ \\
\hline \multicolumn{4}{|l|}{ Experienced homophobia } \\
\hline Score <median (54) & $574(49.1)$ & 65 (11.3) & Referent \\
\hline Score $\geq$ median (54) & $571(48.8)$ & $69(12.1)$ & $1.03(0.74$ to 1.45$)$ \\
\hline \multicolumn{4}{|l|}{ Internalised homophobia } \\
\hline Mean (SD) & $15.6(7.01)$ & $16.1(7.93)$ & $1.01(0.99$ to 1.03$)$ \\
\hline \multicolumn{4}{|l|}{ Internalised homophobia } \\
\hline Score <median (15) & $599(51.2)$ & $70(11.7)$ & Referent \\
\hline Score $\geq$ median (15) & $531(45.4)$ & $61(11.5)$ & $1.06(0.75$ to 1.49$)$ \\
\hline \multicolumn{4}{|l|}{ Partnership type } \\
\hline Men who have sex with men only & $657(56.2)$ & $68(10.4)$ & Referent \\
\hline Men who have sex with men and women & $511(43.7)$ & $70(13.7)$ & $1.45(1.04$ to 2.21$)$ \\
\hline \multicolumn{4}{|l|}{ Lives with primary partner } \\
\hline No & $975(83.4)$ & $111(11.4)$ & Referent \\
\hline Yes & $177(15.1)$ & $24(13.6)$ & $1.17(0.73$ to 1.78$)$ \\
\hline
\end{tabular}


Table 1 Continued

\begin{tabular}{llll}
\hline Characteristic & Total $(\mathbf{N = 1 1 6 9 )}$ & $\begin{array}{l}\mathbf{N}(\%)^{\star}, \mathbf{\dagger} \text { with low social } \\
\text { support (n=138) }\end{array}$ & RR (95\% Cl) \\
\hline City & & & Referent \\
Atlanta & $207(17.7)$ & $18(8.7)$ & $1.61(0.93$ to 2.88$)$ \\
New York City & $256(21.9)$ & $38(14.8)$ & $0.58(0.25$ to 1.27$)$ \\
Washington & $177(15.1)$ & $9(5.1)$ & $1.75(0.95$ to 3.27$)$ \\
Boston & $173(14.8)$ & $24(13.9)$ & $1.34(0.73$ to 2.49$)$ \\
Los Angeles & $207(17.7)$ & $25(12.1)$ & $1.84(1.00$ to 3.44) \\
\hline San Francisco & $149(12.7)$ & $24(16.1)$ & \\
\hline
\end{tabular}

*Totals may not sum to 138 because of missing values.

†Low social support defined as lacking all forms of support at 12 months compared with having at least one form of support at 12 months.

HPTN, HIV Prevention Trials Network; RR, risk ratio.

we presented associations between recent incarceration at 6 months and social support at 12 months among those with and without baseline support in the tables and highlighted these differences in the text when observed.

\section{RESULTS \\ Baseline characteristics among participants with low levels of social support}

Of the analytical sample ( $\mathrm{N}=1169), 14 \%$ participants reported recent incarceration at the 6-month follow-up, and $12 \%$ of participants were categorised as lacking all six forms of social support at 12 months follow-up. In table 1, we present associations between selected covariates (of those included in the IPTW) and low social support. Median age was 39 years and was not associated with low support. Compared with cisgender males, transgender females had approximately twice the risk of low social support (RR 1.94, 95\% CI 0.99 to 3.42). Participants with unstable housing (RR 1.63, 95\% CI 0.99 to 2.56), who dropped out of high school (RR $1.50,95 \%$ CI 1.07 to 2.12 ) and with insufficient income (RR 1.84, 95\% CI 1.29 to 2.66) had higher risk of low support. All the covariates measured as scales were included as such in the IPTW model but in order to illustrate the prevalence of low social support across levels of the scales, we created cut-points based on the median except for depression which is based on the validated cut-point of $\geq 16 .{ }^{35}$ Participants with depressive symptoms had approximately twice the risk of reporting low social support (RR $1.95,95 \%$ CI 1.38 to 2.78 ). Racism, and experienced and internalised homophobia did not appear associated with low social support. Those who have sex with men and women had greater risk of reporting a lack of social support than those who have sex with men only (RR $1.45,95 \%$ CI 1.04 to 2.21). Compared with those living in Atlanta, participants who lived in New York City, Boston and San Francisco had higher risk of low support while those in Washington DC appeared to have lower risk.
Associations between recent incarceration and subsequent social support

Continuous Social Support Score. Among all participants, the mean social support score at 12 months was 20.9 (data not shown in table). Recent incarceration was associated with a lower prevalence of subsequent support (table 2). Specifically, after adjustment, recent incarceration was associated with lower social support (adjusted $\beta$ : $-2.40,95 \%$ CI -3.94 to -0.85$)$. The relationship between recent incarceration and overall social support did not differ based on baseline social support.

Emotional and informational support. Approximately $19 \%$ of the sample reported lacking someone to talk and listen none or little of the time, $28 \%$ lacked someone to give advice, $22 \%$ lacked someone to provide emotional support and $23 \%$ lacked contact with someone they felt close to. Recent incarceration was associated with increased risk of lacking each of these forms of support (table 3). Those who were recently incarcerated had an approximately $50 \%$ higher risk of not having someone to talk and listen at 12 months (adjusted RR (aRR) 1.55, 95\% CI 1.13 to 2.13). Participants who had been incarcerated in the past 6 months had increased risk of lacking someone who could give them advice (aRR 1.73, 95\% CI 1.27 to 2.36). This association appeared stronger among those with that support at baseline (aRR 2.02, 95\% CI 1.27 to 3.21$)$. Similarly, recent incarceration was associated with increased risk of lacking someone to provide emotional support (aRR 1.50, 95\% CI 1.14 to 1.99), and the relationship appeared stronger among those with that support at baseline (no baseline support aRR 1.23, 95\% CI 0.91 to 1.66; baseline support aRR 1.83 , 95\% CI 1.19 to 2.82). Recent incarceration was associated with lacking contact with someone they felt close (aRR 1.42, 95\% CI 1.07 to 1.88 ).

Affectionate support. Approximately $21 \%$ of the sample reporting lacking affectionate support and incarceration was associated with a $50 \%$ increase in risk of lacking that form of support (aRR 1.51, 95\% CI 1.11 to 2.04). 


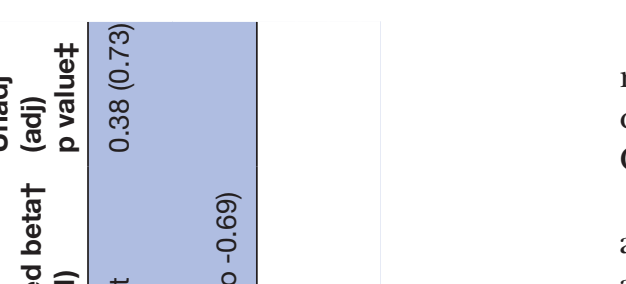

Tangible support. Approximately 36\% of participants reported lacking someone to help with chores and incarceration did not appear to be associated (aRR 1.15, 95\% CI 0.92 to 1.44 ).

Low overall social support. Recent incarceration was associated with approximately 1.8 times the risk of lacking all six forms of social support at 12 months (aRR 1.80, 95\% CI 1.21 to 2.68). The association appeared stronger among those who had had support at baseline compared with those who had not in unadjusted analyses (no baseline support RR 1.14, 95\% CI 0.70 to 1.86 ; baseline support RR 2.11, 95\% CI 1.30 to 3.42) but the difference was not significant after adjustment (no baseline aRR 1.46, $95 \%$ CI 0.93 to 2.29; baseline support aRR 2.07, $95 \%$ CI 1.19 to 3.60 ).

\section{DISCUSSION}

In this sample of BSMM and BTW, those who had been incarcerated in the past 6 months were more likely to have lower levels of social support following incarceration, and to lack specific forms of social support. The negative impact of incarceration on some forms of support appeared stronger for those who had had support at baseline (ie, prior to the recent incarceration), which suggest that the incarceration may have contributed to a reduction in support among those where it had previously been present. Our results extend the body of literature demonstrating incarceration's detrimental impacts on support by highlighting these disruptive effects on support networks of BSMM and BTW, populations that are disproportionately exposed to criminal justice involvement. Findings suggest the importance of identifying opportunities for criminal justice reform and alternatives to incarceration to best protect support networks of BSMM and BTW, whose networks are critical to protecting well-being and health. Findings also highlight the need to help BSMM and BTW who are experiencing incarceration to maintain and strengthen support to promote successful community re-entry and improve health.

In this study, participants were reporting on incarceration occurring between baseline and the 6-month follow-up visit, and this brief reporting period suggests that these were likely short-term incarcerations in jail. Yet, we still found that these incarcerations conferred risk of lacking social support, supporting prior studies showing that incarceration of short duration has just as strong if not stronger adverse effects compared with longer detainments. ${ }^{45}$ Considering that up to three-quarters of individuals in jails have not been convicted of a crime but are denied/unable to make bail, or have been charged with low-level offences, ${ }^{46}$ this highlights the need for bail reform and to find alternatives to incarceration to prevent disruptive impacts on support that may have long-lasting collateral consequences. There is also a clear need for programming to maintain and foster support networks during incarceration, and programmes vary widely by state. Departments of correction characterise visitation as 


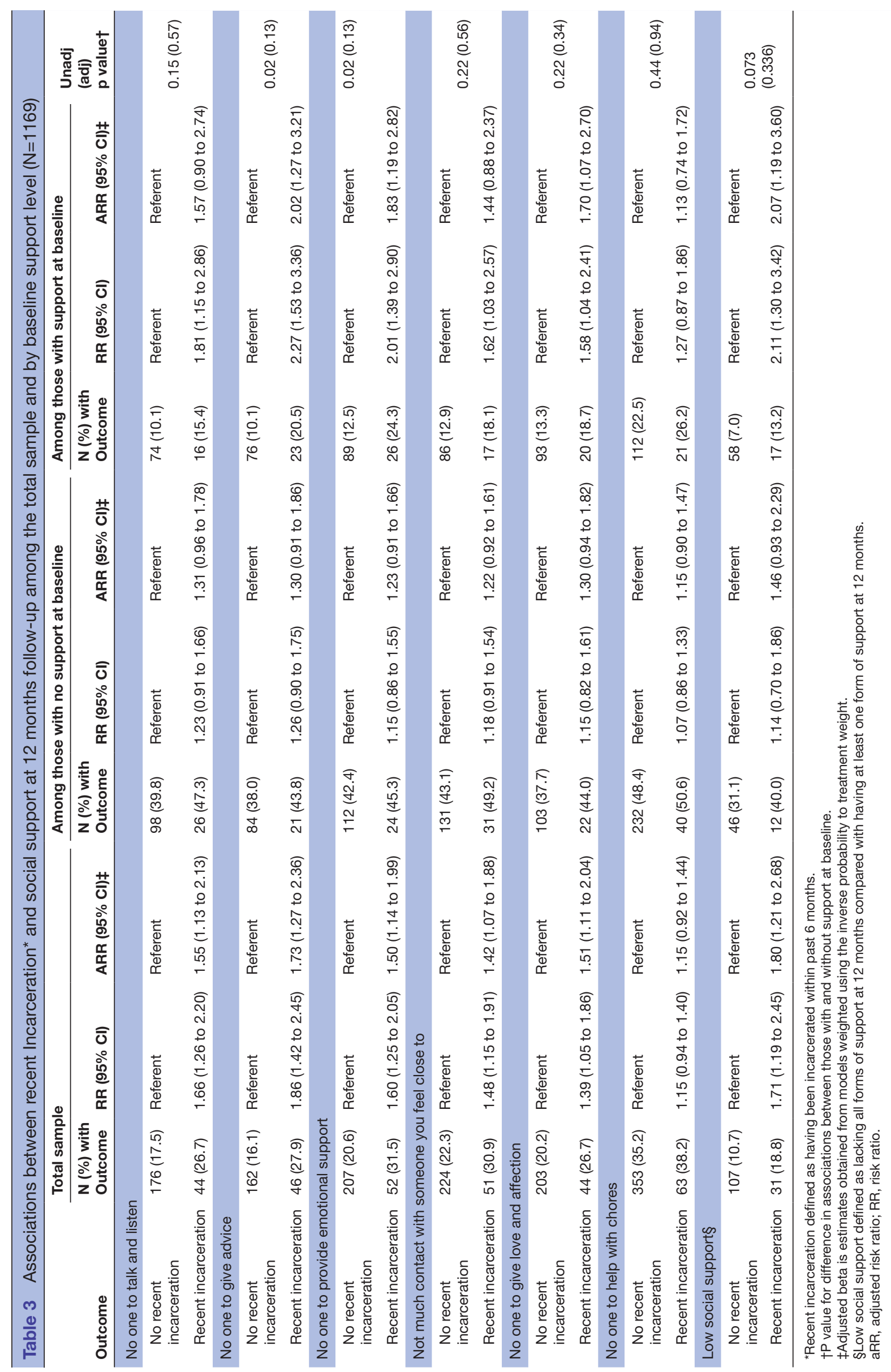


a 'privilege' and this may be further restricted for those seeking visitation from same-sex partners. ${ }^{47}$ Finally, the only known intervention for criminal justice-involved couples, which seeks to enhance relationships to reduce $\mathrm{STI} / \mathrm{HIV}$ risk, is focused on men in community corrections and female partners. ${ }^{48}$

Recent incarceration was linked to lacking someone to give advice. Supportive networks that provide information and advice might be particularly important for BSMM and BTW, potentially even more so after incarceration. Support via provision of information and advice regarding employment and housing opportunities are vital for these groups as they re-enter society and re-establish themselves. ${ }^{149}$ Intersecting potential stigmas experienced as a racial and sexuality minority individual who has been incarcerated may exacerbate needs for advice regarding housing and employment during re-entry. It is unfortunately well documented that employers are often biased against hiring racial and/or sexual minorities, ${ }^{50}$ and a criminal record may worsen this employment discrimination. Having social support to assist with housing and employment must be complemented by policy changes to reduce discrimination in these areas. We also found that those who were recently incarcerated had an almost $50 \%$ increase in risk of being without affectionate support. The majority of people have a romantic partner at prison entry, ${ }^{10} 51$ and partners are often a key source of support. ${ }^{49}$ Disruption of these partnerships during incarceration and subsequently lacking emotional and affectionate support during re-entry is associated with risk of depression, substance use, and STI/HIV. ${ }^{8}$ Moreover, BSMM and BTW often describe family and friends as important sources of support, ${ }^{52}$ and family are vital for providing emotional support to individuals who are incarcerated, ${ }^{49}$ possibly even more so than romantic partners. ${ }^{53}$ Lacking this support could lead to increased risk for poor mental health, substance use, and involvement in exchange sex, thereby increasing risk of adverse outcomes including STI/HIV and risk for recidivism. ${ }^{54}$

A major limitation of this study is that we are not able to determine who the people were providing support. Studies conducted in principally male samples of individuals who were incarcerated have found that specific people such as mother, sisters and romantic partners are often the most crucial sources of support and forms of support received from these sources differed. ${ }^{9955}$ We also lack data regarding the level of communication with support networks during incarceration, including barriers to staying in touch. An additional limitation of our measure of social support is that the six-item scale is not validated, and the items included here as adapted from the MOS social support survey may not capture other dimensions or forms of social support that are important for the health and well-being of BSMM and BTW, and qualitative research is needed to understand this topic and develop social support measures for this population. This information would improve understanding of how to best protect support networks of BSMM and BTW in the context of incarceration. We also do not know the reason for or length of the incarceration or how long since an individual was released, which may have differential impacts on support. HPTN 061 aimed to examine HIV prevention strategies for black gay, bisexual and other sexual minorities individuals when it was conducted approximately ten years ago; however, a small proportion of transgender women were recruited into the study sample. We lacked power to assess differences in associations between BSMM and BTW due to the small number of BTW but it is possible incarceration's impact on social support may differ in these groups and future research is needed. Measures were self-reported and lost to follow-up may have been greater for those with incarceration histories and/or low social support, potentially introducing information and selection bias, respectively. Also, considering the recruitment strategies of the parent study, generalisability may be limited.

This study is the first to our knowledge to demonstrate that incarceration may be associated with lower social support on re-entry among BSMM and BTW, populations that are unequally targeted for criminal justice involvement and potentially already at heightened risk for lacking support. We need future studies to examine how incarceration-induced reductions in social support may have downstream consequences on the health and wellbeing of these groups, which could inform prevention approaches seeking to reduce incarceration's adverse effects.

\section{Author affiliations}

${ }^{1}$ Population Health, New York University School of Medicine, New York, New York, USA

${ }^{2}$ School of Public Health, Epidemiology and Biostatistics, University of Maryland at College Park, College Park, Maryland, USA

${ }^{3}$ Prevention and Care Division, Black AIDS Institute, Los Angeles, California, USA ${ }^{4}$ Harvard University T H Chan School of Public Health, Boston, Massachusetts, USA ${ }^{5}$ The Fenway Institute, Fenway Health, Boston, Massachusetts, USA

Acknowledgements This manuscript is a product of authors and has not been reviewed by and does not necessarily represent the views of the HPTN 061 protocol team, the HPTN or the study sponsor/funders. We are thankful to the following groups who made possible the HIV Prevention Trials Network 061 (HPTN 061) study: HPTN 061 study participants; HPTN 061 Protocol co-chairs, Beryl Koblin, PhD, Kenneth Mayer, MD, and Darrell Wheeler, PhD, MPH; HPTN061 Protocol team members; HPTN Black Caucus; HPTN Network Laboratory, Johns Hopkins University School of Medicine; Vaccine and Infectious Disease Division, Fred Hutchinson Cancer Research Center; Statistical and Data Management Center, Statistical Center for HIV/AIDS Research and Prevention; HPTN CORE Operating Center, Family Health International (FHI) 360; Black Gay Research Group; clinical research sites, staff, and Community Advisory Boards at Emory University, Fenway Institute, GWU School of Public Health and Health Services, Harlem Prevention Center, New York Blood Center, San Francisco Department of Public Health, the University of California, Los Angeles, Center for Behavioral and Addiction Medicine, and Cornelius Baker, FHI 360. We are thankful to Sam Griffith, Senior Clinical Research Manager, FHI 360, and Lynda Emel, Associate Director, HPTN Statistical and Data Management Center, Fred Hutchinson Cancer Research Center, for their considerable assistance with HPTN 061 data acquisition and documentation. 
Contributors JS assisted in conceptualising the analysis and wrote the first draft of the manuscript; TVD, $\mathrm{CH}-0$ and JA wrote sections of the manuscript; MM, CC and RET provided statistical expertise and conducted the analyses; NI and MS participated in reviewing the literature and writing the manuscript; KM is the protocol chair for HPTN 061, assisted in conceptualising the analysis and contributed to writing the manuscript; MK is the principal investigator of the secondary data analysis study, assisted in conceptualising and guiding the analysis, and contributed to writing the manuscript. All authors revised subsequent drafts and approved of the final version of the manuscript.

Funding This research was supported by the National Institute on Drug Abuse grant 'Stop-and-Frisk, Arrest and Incarceration and STI/HIV Risk in Minority SMM' (Principal Investigator: MRK; R01DA044037). This research uses data from the HPTN 061 study. HPTN 061 grant support was provided by the National Institute of Allergy and Infectious Disease (NIAID), National Institute on Drug Abuse (NIDA) and National Institute of Mental Health (NIMH): Cooperative Agreements UM1 Al068619, UM1 Al068617 and UM1 Al068613. Additional site funding included Fenway Institute Clinical Research Site (CRS): Harvard University CFAR (P30 Al060354) and CTU for HIV Prevention and Microbicide Research (UM1 Al069480); George Washington University CRS: District of Columbia Developmental CFAR (P30 Al087714); Harlem Prevention Center CRS and NY Blood Center/Union Square CRS: Columbia University CTU (5U01 Al069466) and ARRA funding (3U01 Al069466-03S1); Hope Clinic of the Emory Vaccine Center CRS and The Ponce de Leon Center CRS: Emory University HIV/AIDS CTU (5U01 Al069418), CFAR (P30 Al050409) and CTSA (UL1 RR025008); San Francisco Vaccine and Prevention CRS ARRA funding (3U01 Al069496-03S1, 3U01 Al069496-03S2); UCLA Vine Street CRS: UCLA Department of Medicine, Division of Infectious Diseases CTU (U01 Al069424). MK, CC and JS received support from the New York University Center for Drug Use and HIV Research (P30 DA011041). MK additionally was supported by the New York UniversityCity University of New York (NYU-CUNY) Prevention Research Center (U48 DP005008). TVD and RET were supported by the University of Maryland Prevention Research Center, cooperative agreement \#U48 DP006382 from the Centers for Disease Control and Prevention (CDC). Any interpretations and opinions expressed herein are solely those of the authors and may not reflect those of the CDC.

Disclaimer The funder had a role in the design of the study by providing input into the design. The funder did not have a role in the data collection and analysis, decision to publish, or preparation of the manuscript. The funding agencies had no role in designing the research, data analyses and preparation of the report.

Competing interests None declared.

Patient consent for publication Not required.

Ethics approval Institutional review boards at the participating institutions approved the parent study and all participants consented to participate in the parent study; NYU Grossman School of Medicine does not consider analysis of deidentified data to be human subjects research and hence the current analysis did not require review.

Provenance and peer review Not commissioned; externally peer reviewed.

Data availability statement Data may be obtained from a third party and are not publicly available. Data are available upon request from HPTN 061.

Supplemental material This content has been supplied by the author(s). It has not been vetted by BMJ Publishing Group Limited (BMJ) and may not have been peer-reviewed. Any opinions or recommendations discussed are solely those of the author(s) and are not endorsed by BMJ. BMJ disclaims all liability and responsibility arising from any reliance placed on the content. Where the content includes any translated material, BMJ does not warrant the accuracy and reliability of the translations (including but not limited to local regulations, clinical guidelines, terminology, drug names and drug dosages), and is not responsible for any error and/or omissions arising from translation and adaptation or otherwise.

Open access This is an open access article distributed in accordance with the Creative Commons Attribution Non Commercial (CC BY-NC 4.0) license, which permits others to distribute, remix, adapt, build upon this work non-commercially, and license their derivative works on different terms, provided the original work is properly cited, appropriate credit is given, any changes made indicated, and the use is non-commercial. See: http://creativecommons.org/licenses/by-nc/4.0/.

ORCID iD

Joy D Scheidell http://orcid.org/0000-0001-5504-149X
REFERENCES

1 Ozbay F, Johnson DC, Dimoulas E. Social support and resilience to stress: from neurobiology to clinical practice. Psychiatry 2007;4:35-40.

2 Nguyen AW, Chatters LM, Taylor RJ, et al. Social support from family and friends and subjective well-being of older African Americans. $J$ Happiness Stud 2016;17:959-79.

3 Cohen S, Wills TA, Stress WTA. Stress, social support, and the buffering hypothesis. Psychol Bull 1985;98:310-57.

4 Glanz K, Rimer BK, Viswanath K. Health behavior: theory, research, and practice. 5th ed. San Francisco, CA: Jossey bass, 2015.

5 Reblin M, Uchino BN. Social and emotional support and its implication for health. Curr Opin Psychiatry 2008;21:201-5.

6 Taylor CJ. The Family's Role in the Reintegration of Formerly Incarcerated Individuals: The Direct Effects of Emotional Support. The Prison Journal 2016;96:331-54.

7 Wolff N, Draine J. Dynamics of social capital of prisoners and community reentry: ties that bind? Journal of Correctional Health Care 2004; 10:457-90.

8 Khan MR, Scheidell JD, Golin CE, et al. Dissolution of committed partnerships during incarceration and STI/HIV-Related sexual risk behavior after prison release among African American men. J Urban Health 2018;95:479-87.

9 Coatsworth AM, Scheidell JD, Wohl DA, et al. Hiv-Related sexual risk among African American men preceding incarceration: associations with support from significant others, family, and friends. J Urban Health 2017;94:136-48.

10 Morrow KM, Project START Study Group. Hiv, STD, and hepatitis risk behaviors of young men before and after incarceration. AIDS Care 2009;21:235-43.

11 Khan MR, Behrend L, Adimora AA, et al. Dissolution of primary intimate relationships during incarceration and implications for postrelease HIV transmission. J Urban Health 2011;88:365-75.

12 Khan MR, Behrend L, Adimora AA, et al. Dissolution of primary intimate relationships during incarceration and associations with post-release STI/HIV risk behavior in a southeastern City. Sex Transm Dis 2011;38:43-7.

13 Comfort M, Krieger KE, Landwehr J, et al. Partnership after prison: couple relationships during reentry. J Offender Rehabil 2018;57:188-205.

14 Berg MT, Huebner BM. Reentry and the ties that bind: an examination of social ties, employment, and recidivism. Justice Quarterly 2011;28:382-410.

15 Meyer IH, Flores AR, Stemple L, et al. Incarceration rates and traits of sexual minorities in the United States: national inmate survey, 20112012. Am J Public Health 2017;107:267-73.

16 Travis J, Western B, Redburn S. The growth of incarceration in the United States: exploring causes and consequences. Washington, D.C.: The National Academies Press, 2014.

17 Schnittker J, John A. Enduring stigma: the long-term effects of incarceration on health. $J$ Health Soc Behav 2007;48:115-30.

18 Moore KE, Tangney JP, Stuewig JB. The Self-Stigma process in criminal offenders. Stigma Health 2016;1:206-24.

19 Travis J, McBride EC, Solomon AL. Families left behind: the hidden costs of incarceration and reentry 2005.

20 Crenshaw K. Demarginalizing the intersection of race and sex: a black feminist critique of Antidiscrimination doctrine, feminist theory and Antiracist politics. The University of Chicago Legal Forum 1989;140:139-67.

21 Bowleg L. "Once You've Blended the Cake, You Can't Take the Parts Back to the Main Ingredients": Black Gay and Bisexual Men's Descriptions and Experiences of Intersectionality. Sex Roles 2013;68:754-67.

22 Mays VM, Tiers LMC, Cochran SD, et al. African American families in diversity: gay men and lesbians as participants in family networks. $J$ Comp Fam Stud 1998;29:73-87.

23 Díaz RM, Ayala G, Bein E, et al. The impact of homophobia, poverty, and racism on the mental health of gay and bisexual Latino men: findings from 3 us cities. Am J Public Health 2001;91:927-32.

24 Koblin BA, Mayer KH, Eshleman SH, et al. Correlates of HIV acquisition in a cohort of black men who have sex with men in the United States: HIV prevention trials network (HPTN) 061. PLoS One 2013;8:e70413

25 Sherbourne CD, Stewart A. The mos social support survey, 1993. Available: https://www.rand.org/pubs/reprints/RP218.htm

26 Sherbourne CD, Stewart AL. The MOS social support survey. Soc Sci Med 1991;32:705-14.

27 Turpin R, Dyer T, Watson L, et al. Classes of sexual identity, homophobia, and sexual risk among black sexual minorities in HPTN 061. J Sex Res 2021;58:638-47. 
28 Hall GC, Young A, Krakauer C, et al. Sexual risk behaviors among black men who have sex with men who also report having sex with transgender partners: analysis of HIV prevention trials network (HPTN) 061 study. AIDS Educ Prev 2017;29:418-31.

29 Scholz U, Kliegel M, Luszczynska A, et al. Associations between received social support and positive and negative affect: evidence for age differences from a daily-diary study. Eur J Ageing 2012;9:361-71.

30 Gabrielian S, Hamilton AB, Gelberg L, et al. Identifying social skills that support housing attainment and retention among homeless persons with serious mental illness. Psychiatr Serv 2019;70:374-80.

31 Bøen H, Dalgard OS, Bjertness E. The importance of social support in the associations between psychological distress and somatic health problems and socio-economic factors among older adults living at home: a cross sectional study. BMC Geriatr 2012;12:27.

32 Gass BV, Horvath KJ, Marrow E, et al. Associations between social support availability and HIV risk and protective factors in a U.S. sample of adults with diverse transgender identities. LGBT Health 2021;8:60-7.

33 Saunders JB, Aasland OG, Babor TF, et al. Development of the alcohol use disorders identification test (audit): who Collaborative project on early detection of persons with harmful alcohol Consumption-II. Addiction 1993;88:791-804.

34 Hunter-Reel D, McCrady BS, Hildebrandt T, et al. Indirect effect of social support for drinking on drinking outcomes: the role of motivation. J Stud Alcohol Drugs 2010;71:930-7.

35 Radloff LS, Rae DS. Susceptibility and precipitating factors in depression: sex differences and similarities. J Abnorm Psychol 1979;88:174-81.

36 Dyer TV, Feelemyer J, Scheidell JD, et al. Estimating the influence of incarceration on subsequent experience with violence among black men who have sex with men in the HPTN061 study. J Interpers Violence 2021;8862605211021970:8862605211021970.

37 Harrell SP. Psychometric properties of the racism and life experience scale. annual convention of the American psychological association. Chicago, IL, 1997.

38 Remch M, Duncan DT, Geller A, et al. Police harassment and psychosocial vulnerability, distress, and depressive symptoms among black men who have sex with men in the U.S.: longitudinal analysis of HPTN 061. SSM Popul Health 2021;13:100753.

39 Herek GM, Glunt EK. An epidemic of stigma. public reactions to AIDS. Am Psychol 1988;43:886-91.

40 Severe M, Scheidell JD, Dyer TV, et al. Lifetime burden of incarceration and violence, internalized homophobia, and HIV/STI risk among black men who have sex with men in the HPTN 061 study. AIDS Behav 2021;25:1507-17.

41 Frost DM, Meyer IH, Schwartz S. Social support networks among diverse sexual minority populations. Am J Orthopsychiatry 2016;86:91-102.
42 Agnew-Brune CB, Balaji AB, Mustanski B, et al. Mental health, social support, and HIV-related sexual risk behaviors among HIV-negative adolescent sexual minority males: three U.S. cities, 2015. AIDS Behav 2019;23:3419-26.

43 Hernán MA, Robins JM. Estimating causal effects from epidemiological data. J Epidemiol Community Health 2006;60:578-86.

44 Rubin DB. Multiple imputation for nonresponse in surveys. Hoboken, NJ: John Wiley, 2011.

45 Khan MR, Epperson MW, Mateu-Gelabert P, et al. Incarceration, sex with an STI- or HIV-infected partner, and infection with an STI or HIV in Bushwick, Brooklyn, NY: a social network perspective. Am J Public Health 2011;101:1110-7.

46 Sawyer W, Wagner P. Mass incarceration: the whole pie 2020, 2020. Available: https://www.prisonpolicy.org/reports/pie2020.html [Accessed May 2020].

47 Boudin C, Stutz T, Littman A. Prison visitation policies: a Fifty-State survey 2013;1.

48 El-Bassel N, Gilbert L, Goddard-Eckrich D, et al. Effectiveness of a Couple-Based HIV and sexually transmitted infection prevention intervention for men in community supervision programs and their female sexual partners: a randomized clinical trial. JAMA Netw Open 2019;2:e191139.

49 Western B, Braga AA, Davis J, et al. Stress and hardship after prison. AJS 2015;120:1512-47.

50 Cunningham GB, Sartore ML, McCullough BP. The influence of applicant sexual orientation, applicant gender, and Rater gender on ascribed Attributions and hiring recommendations of personal trainers. Journal of Sport Management 2010;24:400-15.

51 Grinstead OA, Faigeles B, Comfort M, et al. Hiv, STD, and hepatitis risk to primary female partners of men being released from prison. Women Health 2005;41:63-80.

52 Saleh LD, van den Berg JJ, Chambers CS, et al. Social support, psychological vulnerability, and HIV risk among African American men who have sex with men. Psychol Health 2016;31:549-64.

53 Martinez DJ, Christian J. The familial relationships of former prisoners: examining the link between residence and informal support mechanisms. Journal of Contemporary Ethnography 2009;38:201-24.

54 Sugie NF, Dallas A. Social support in daily life at reentry. beyond recidivism: new approaches to research on prisoner reentry and reintegration 2020;197.

55 Seal DW, Eldrige GD, Kacanek D, et al. A longitudinal, qualitative analysis of the context of substance use and sexual behavior among 18- to 29-year-old men after their release from prison. Soc Sci Med 2007;65:2394-406. 